\title{
Size Evolution Dynamics of Gold Nanoclusters at Atom- Precision Level: Ligand Exchange, Growth Mechanism, Electrochemical and Photo-Physical Properties
}

\author{
Manju P. Maman ${ }^{\mathrm{a} \dagger}$, Akhil S. Nair ${ }^{\mathrm{b} \dagger}$, Haritha Cheraparambil ${ }^{\mathrm{a}}$, Biswarup Pathak ${ }^{\mathrm{b}^{\star}}$ and Sukhendu \\ Mandal $^{\mathrm{a}^{*}}$ \\ aSchool of Chemistry, Indian Institute of Science Education and Research Thiruvananthapuram, \\ Maruthamala P.O, Trivandrum, India-695551 \\ Email: sukhendu@iisertvm.ac.in \\ ${ }^{b}$ Discipline of Chemistry, School of Basic Sciences, Indian Institute of Technology Indore, \\ Indore, India \\ Email: biswarup@iiti.ac.in \\ ${ }^{\dagger}$ Both MPM and ASN made equal contribution to this work
}




\section{Materials}

Tetrachloroauric (III) acid trihydrate $\left(\mathrm{HAuCl}_{4} \cdot 3 \mathrm{H}_{2} \mathrm{O},>99.99 \%\right.$ metals basis), Cyclohexanethiol (CySH, $98 \%$ ), sodium borohydride $\left(\mathrm{NaBH}_{4}, 99.99 \%\right.$, trace metal basis), tetraoctylammonium bromide (TOAB, 98\%), 4-tert-butylbenzenethiol (TBBT, $97 \%$ ), trans-2-[3-(4-tert-butylphenyl)2-methyl-2 propenylidene] malononitrile (DCTB, > 99.0 \%) were purchased from Sigma Aldrich. Solvents used were $\mathrm{MeOH}$ (HPLC grade, $99.9 \%$, Spectrochem), ethanol (absolute, Emsure), toluene (HPLC grade, $99.9 \%$, Spectrochem), Dimethylene chloride (DCM, HPLC grade, $99.9 \%$, Spectrochem).

\section{Synthesis of $\left[\mathrm{Au}_{23}\left(\mathrm{C}_{6} \mathrm{H}_{11} \mathrm{~S}\right)\right]^{-}$nanocluster}

According to the reported procedure, $\mathrm{HAuCl}_{4} \cdot 3 \mathrm{H} 2 \mathrm{O}(0.3 \mathrm{mmol}, 118 \mathrm{mg})$ and tetraoctylammonium bromide (TOAB, $0.348 \mathrm{mmol}, 190 \mathrm{mg}$ ) were dissolved in methanol $(15 \mathrm{~mL})$ in a $50 \mathrm{~mL}$ roundbottom flask. After vigorously stirring for $15 \mathrm{~min}$, the solution color changed from yellow to dark reddish orange. Then, excess 1- cyclohexanethiol $(1.6 \mathrm{mmol}, 196 \mu \mathrm{L})$ was added to the mixture at room temperature. The reddish orange solution turned yellowish. After $\sim 15 \mathrm{~min}, \mathrm{NaBH}_{4}(3 \mathrm{mmol}$, $114 \mathrm{mg}$ dissolved freshly in $6 \mathrm{~mL}$ of cold Nanopure water) was rapidly added to the solution under vigorous stirring. The solution turned black immediately indicating formation of Au clusters, which then precipitated out of the methanol solution. The reaction mixture was further allowed to stir overnight and finally gave rise to pure $\left[\mathrm{Au}_{23}\left(\mathrm{C}_{6} \mathrm{H}_{11} \mathrm{~S}\right)_{16}\right]^{-}$nanoclusters. The obtained product was washed with methanol for several times. Then single crystal growth of the nanoclusters was performed by first dissolving $4 \mathrm{mg}\left[\mathrm{Au}_{23}\left(\mathrm{C}_{6} \mathrm{H}_{11} \mathrm{~S}\right)_{16}\right]^{-}$clusters in $1 \mathrm{~mL}$ dichloromethane. This was followed by vapor diffusion of pentane into the cluster solution for 1-2 days. ${ }^{\mathrm{S} 1}$

\section{Ligand Exchange with TBBT}

Single crystal of $\left[\mathrm{Au}_{23}\left(\mathrm{C}_{6} \mathrm{H}_{11} \mathrm{~S}\right)_{16}\right]^{-}(5 \mathrm{mg})$ was dissolved in $1 \mathrm{~mL}$ toluene. Then $0.5 \mathrm{~mL}$ TBBT was added and the reaction mixture was stirred at $1200 \mathrm{rpm}$ for $1 \mathrm{~h}$ at $80^{\circ} \mathrm{C}$. After that, the solution was cooled down to RT, centrifuged and excess $15 \mathrm{~mL}$ methanol was added to the supernatant to precipitate out the cluster. The so obtained cluster was washed thrice with $30 \mathrm{~mL}$ methanol and

dried at room temperature. Yield of the reaction was $80 \%$ (each $5 \mathrm{mg}$ of $\mathrm{Au}_{23}$ cluster produced $3.9 \mathrm{mg}$ of the ligand exchanged product). 


\section{Characterization techniques}

The absorption spectra were collected at room temperature on a UV-3800 SHIMADZU UV-Vis NIR spectrometer using a $3.5 \mathrm{~mL}$ cuvette and toluene as solvent. The mass spectrum of the cluster samples were collected using Bruker microflex MALDI-TOF mass spectrometer. The matrix used was DCTB and a stock solution of DCTB was prepared with a concentration of $20 \mathrm{mg}$ in $1 \mathrm{~mL}$ DCM. The sample was prepared as $1 \mathrm{mg}$ in $100 \mu \mathrm{L}$ DCM. From the stock solution, various amounts of matrix solution were taken and mixed with $1 \mu \mathrm{L}$ of analyte solution. The molecules were ionized with the Nd: YAG laser $(\lambda=266 \mathrm{~nm})$. The matrix concentration was varied for optimization to get a good resolved spectrum. Emission measurements are performed using a Fluorolog-3 spectrofluorimeter from Horiba Jobin Yvon where cluster were dissolved in $\mathrm{CH}_{2} \mathrm{Cl}_{2}$ solution. The emission lifetimes were estimated using a picosecond time correlated single photoncounting system (TCSPC, model Horiba Jobin Yvon-IBH). The samples were excited at $478 \mathrm{~nm}$ using a pulsed diode laser and the repetition rate was fixed at $1 \mathrm{MHz}$. The luminescence lifetime values were evaluated using DAS6.3 fluorescence decay analysis software.

\subsection{Electrochemical studies (Differential Pulse Voltammogram)}

All electrochemical experiments were performed using three electrode system with $\mathrm{CH}$ instrument, where Platinum disk (1.5 mm. diameter) was used as a working electrode, another platinum electrode served as a counter electrode and silver wire was used as a pseudo reference electrode in dichloromethane solvent. In this organic solvent, we have taken $0.5 \mathrm{M}$ tetra butyl-ammoniumperchloride salt as a supporting electrolyte. Every differential pulse voltammogram (DPV) analysis for finding band gap of clusters, we have taken $10 \mathrm{mg}$ of each gold clusters in $5 \mathrm{~mL}$ of the same solvent with supporting electrolyte. 


\section{Computational Details}

The DFT calculations were done using Gaussian 09 D.01 program. ${ }^{\text {S2 }}$ Perdew, Burke and Ernzerhof (PBE) functional ${ }^{\mathrm{S} 3}$ with Pople's $6-31 \mathrm{G}^{*}$ basis set ${ }^{\mathrm{S} 4, \mathrm{~S} 5}$ was used for non-metal elements and LANL2DZ-ECP (effective core potential) ${ }^{\mathrm{S} 6, \mathrm{~S} 7}$ was employed for gold atoms, respectively. Grimme's DFT-D3 method ${ }^{\mathrm{S} 8}$ was used to account for dispersion corrections. Toluene solvent was considered to simulate the experimental non-polar solvent scenario. The TD-DFT calculations considered 300 singlet-to-singlet excitation energies. The Scy and TBBT ligands are simplified to methyl groups during the calculation. Kohn-Sham orbital analysis has been performed for identifying the orbital contribution in each MO and corresponding energies by using multi wave function 3.6 program. ${ }^{\mathrm{S}, \mathrm{S} 10}$

\section{References}

S1. Das, A.; Li, T.; Nobusada, K.; Zeng, C.; Rosi, N. L.; Jin, R. J. Am. Chem. Soc. 2013, 135, 18264-18267.

S2. Frisch, M. J. et al., Gaussian Revision D.01, Gaussian, Inc., Wallingford CT, 2009.

S3. Perdew, J. P.; Burke, K.; Ernzerhof, M. Generalized gradient approximation made simple, Phys. Rev. Lett, 1996, 77, 3865-68.

S4. McLean, A. D; Chandler, G. S. Contracted Gaussian Basis Sets for Molecular Calculations. I. Second Row Atoms, Z = 11 -18. J. Chem. Phys. 1980, 72, 5639 -5648.

S5. Krishnan, R.; Binkley, J. S.; Seeger, R.; Pople, J. A. Selfconsistent molecular orbital methods. XX. A basis set for correlated wave functions. J. Chem. Phys. 1980, 72, 650-654.

S6. Hay, P. J.; Wadt, W. R. Ab Initio Effective Core Potentials for Molecular Calculations. Potentials for the Transition Metal Atoms Sc to Hg. J. Chem. Phys. 1985, 82, $270-283$.

S7. Hay, P. J.; Wadt, W. R. Ab Initio Effective Core Potentials for Molecular Calculations. Potentials for K to Au Including the Outermost Core Orbitals. J. Chem. Phys. 1985, 82, $299-310$. 
S8. Grimme, S.; Antony, J.; Ehrlich, S.; Krieg, H. A consistent and accurate ab initio parametrization of density functional dispersion correction (DFT-D) for the 94 elements H-Pu J. Chem. Phys. 2010, 132, 154104.

S9. $\quad \mathrm{Lu}, \mathrm{T}$;; Chen, F. Multiwfn: A multifunctional wavefunction analyzer. J. Comput. Chem. 2012, 33: 580-592.

S10. Lu, T.; Chen, F. Calculation of Molecular Orbital Composition, Acta Chim. Sinica, 2011, 69, 2393-2406. 

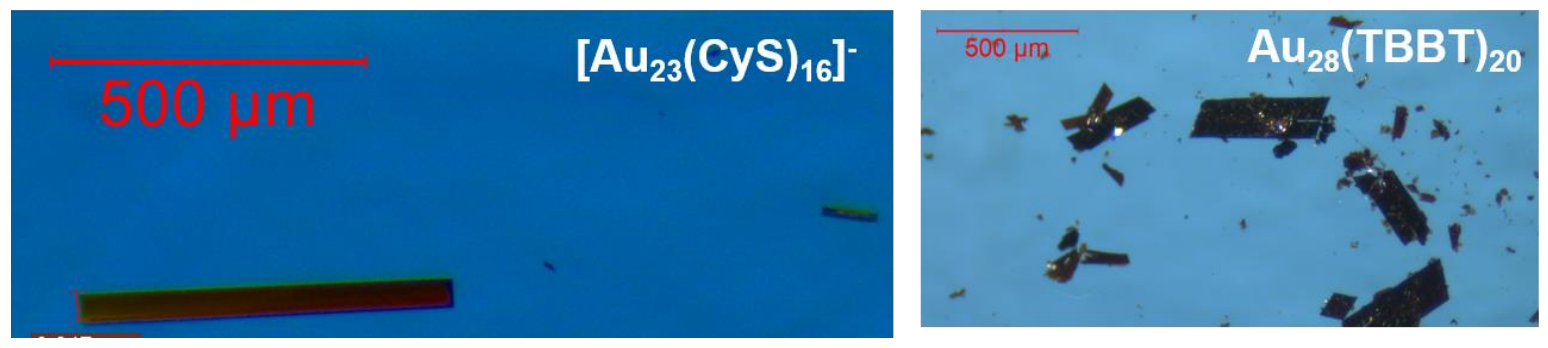

Figure S1: Image showing single crystals of $\mathrm{Au}_{23}$ and $\mathrm{Au}_{28}$ nanoclusters, respectively.

Table S1: Unit cell parameter of the $\mathrm{Au}_{23}$ and Au28 nanocluster, respectively. ${ }^{[\mathrm{a}, \mathrm{b}]}$

\begin{tabular}{|c|l|c|l|}
\hline \multicolumn{2}{|c|}{$\left[\mathbf{A u}_{\mathbf{2 3}}(\mathbf{C y S})_{\mathbf{1 6}}\right]^{-}$} & \multicolumn{2}{c|}{$\mathbf{A u}_{\mathbf{2 8}}(\mathbf{T B B T})_{\mathbf{2 0}}$} \\
\hline Unit cell parameter & \multicolumn{2}{|c|}{ Unit cell parameter } \\
\hline $\mathrm{a}(\AA)$ & 33.86 & $\mathrm{a}(\AA)$ & 16.96 \\
\hline $\mathrm{b}(\AA)$ & 65.3 & $\mathrm{~b}(\AA)$ & 38.6 \\
\hline $\mathrm{c}(\AA)$ & 33.15 & $\mathrm{c}(\AA)$ & 24.01 \\
\hline$\alpha\left(^{\circ}\right)$ & 90 & $\alpha\left(^{\circ}\right)$ & 68.2 \\
\hline$\beta\left(^{\circ}\right)$ & 90 & $\beta\left(^{\circ}\right)$ & 73.3 \\
\hline$\gamma\left({ }^{\circ}\right)$ & 90 & $\gamma\left(^{\circ}\right)$ & 72.4 \\
\hline Volume & 70684 & volume & 13430 \\
\hline Crystal system & Orthorhombic & Crystal system & Triclinic \\
\hline & & & \\
\hline
\end{tabular}

[a] The cell parameters for both the clusters are matching quite well with the reported crystal data. As the structures are reported, we have not collected the full data.

[b] In case of $\mathrm{Au}_{36}(\mathrm{TBBT})_{24}$ cluster, we observed very tiny poor quality crystals and did not observed any diffraction spot. Hence, purity was confirmed through MALDI-MS and UV-Vis data. 


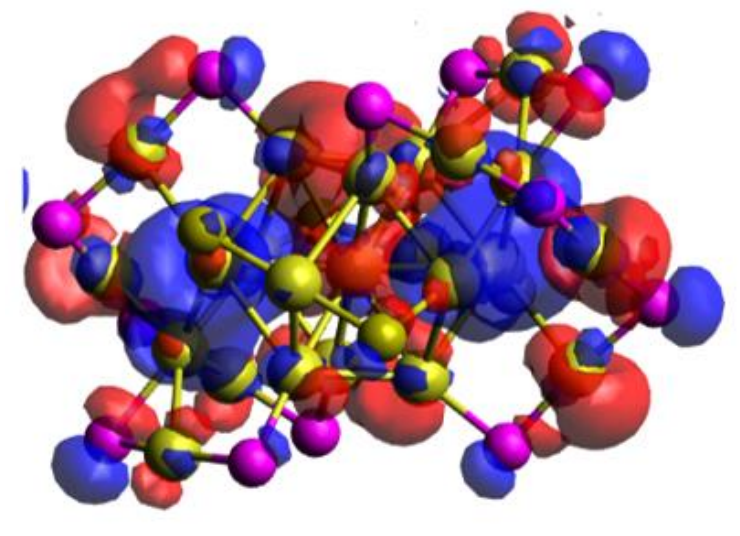

HOMO

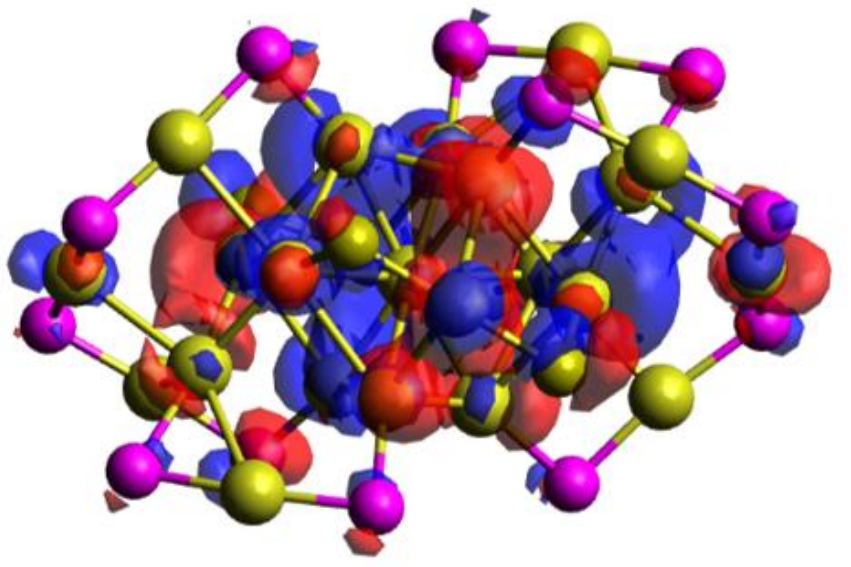

LUMO

Figure S2: The electron density diagram of frontier molecular orbitals of [Au23(SMe) $\left.{ }_{16}\right]^{-}$cluster constructed with an isosurface value of $0.015 \mathrm{eV} \AA^{-3}$. The blue and red colors represent positive and negative isosurfaces. The golden yellow and pink atoms represent Gold and Sulphur atoms, respectively. The carbon and hydrogen atoms of thiol ligands are not represented for visualization convenience. 

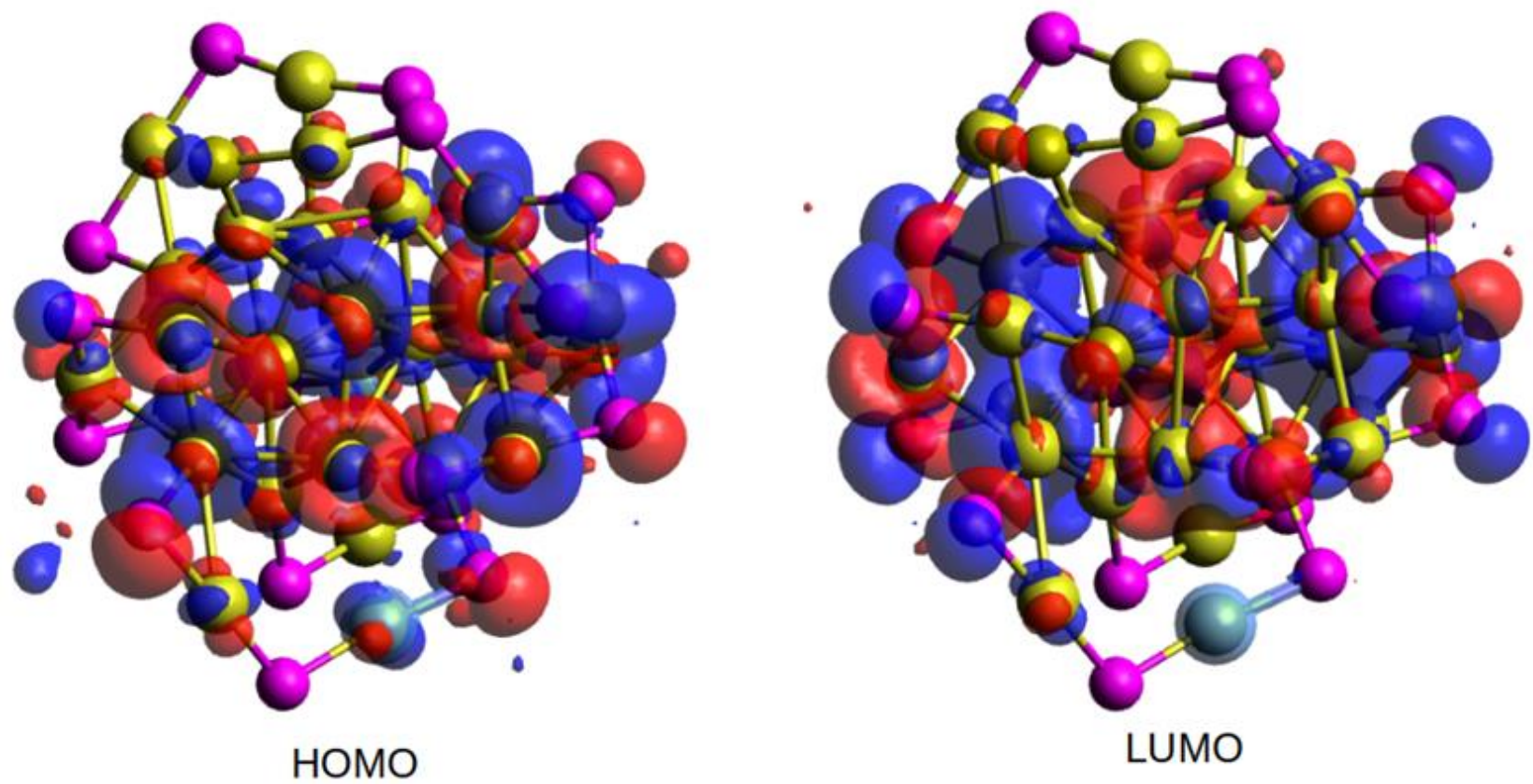

Figure S3: The electron density diagram of frontier molecular orbitals of $\mathrm{Au}_{28}(\mathrm{SMe})_{20}$ cluster constructed with an isosurface value of $0.015 \mathrm{eV} \AA^{-3}$. The blue and red colors represent positive and negative isosurfaces. The golden yellow and pink atoms represent Gold and Sulphur atoms, respectively. The carbon and hydrogen atoms of thiol ligands are not represented for visualization convenience. 


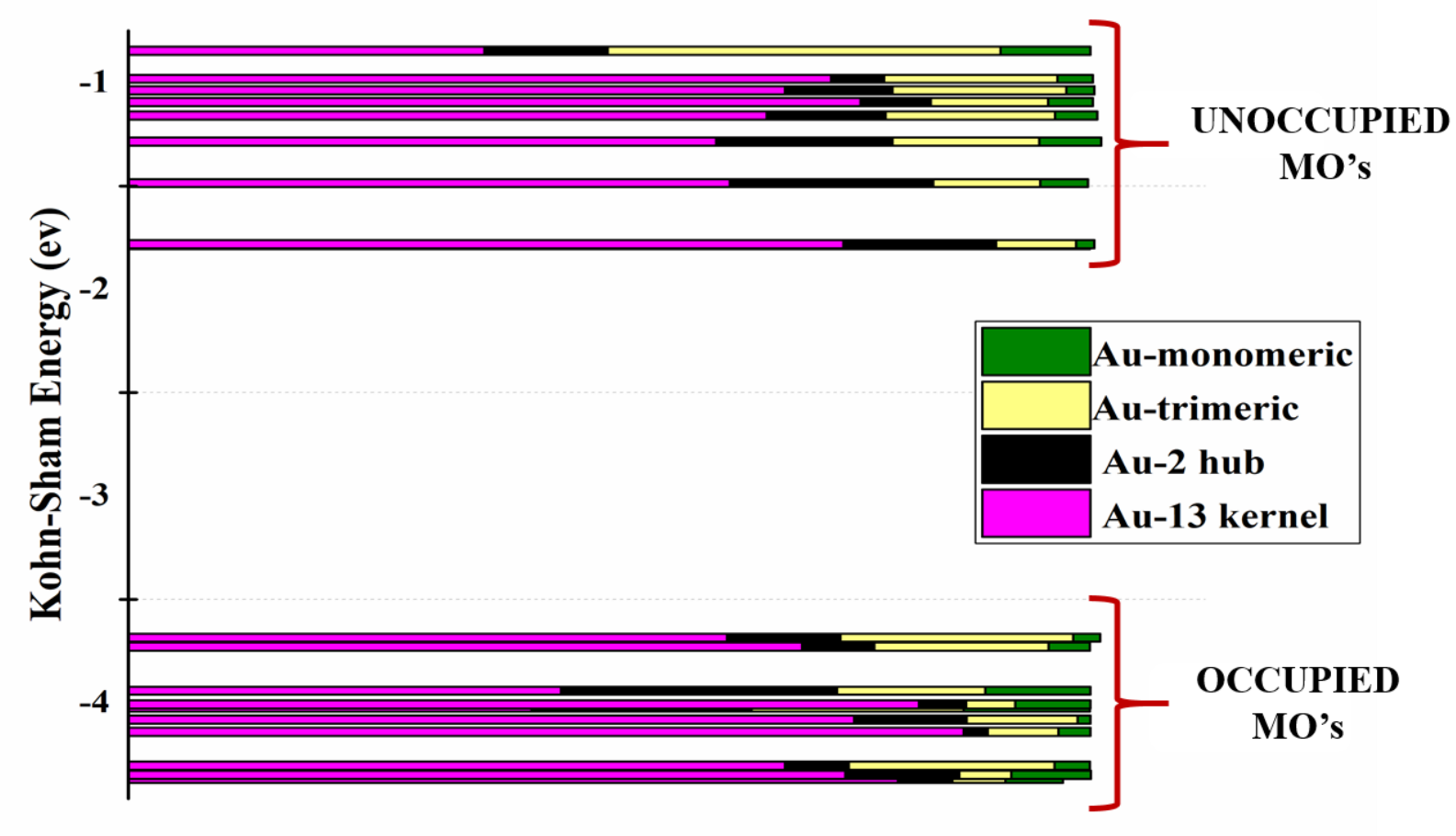

Figure S4. Relative contribution of different type of Gold atoms constituting the molecular orbitals of $\left[\mathrm{Au}_{23}(\mathrm{SCy})_{16}\right]^{-}$cluster. The color code is; $\mathrm{Au}_{13}$ kernel (pink), $\mathrm{Au}_{2}$ hub (black), $\mathrm{Au}_{3}(\mathrm{SR})_{4}$ (yellow) and $\mathrm{Au}(\mathrm{SR})_{2}$ (green). 


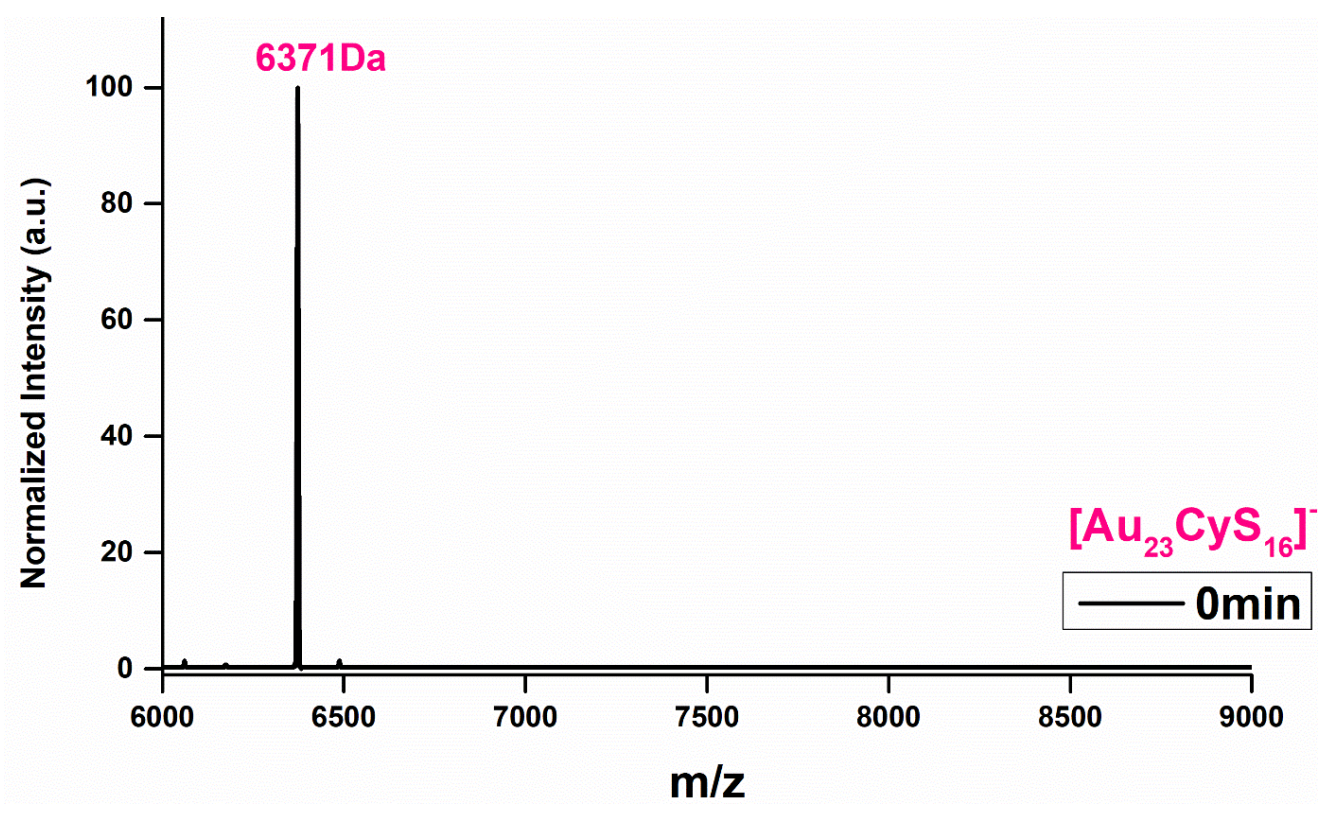

Figure S5. MALDI-MS data of the $\left[\mathrm{Au}_{23}(\mathrm{SCy})_{16}\right]^{-}$cluster showing the purity of the precursor. 


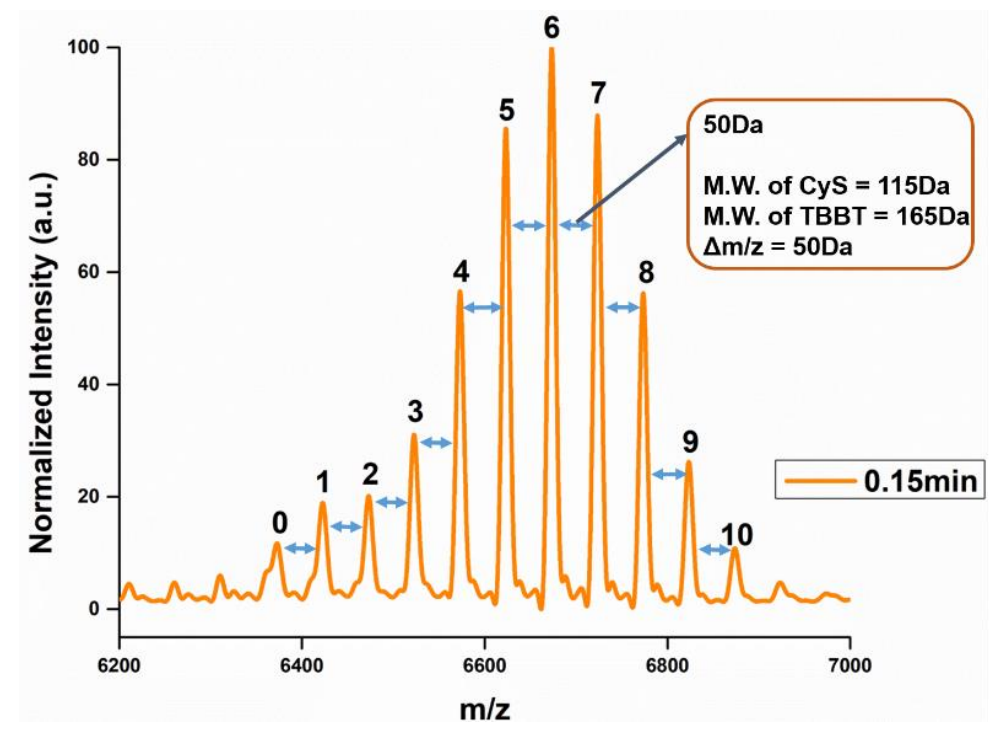

Figure S6. MALDI-MS data showing isotopic distribution of $\mathrm{Au}_{23}$ during Ligand Exchange reaction with TBBT. 


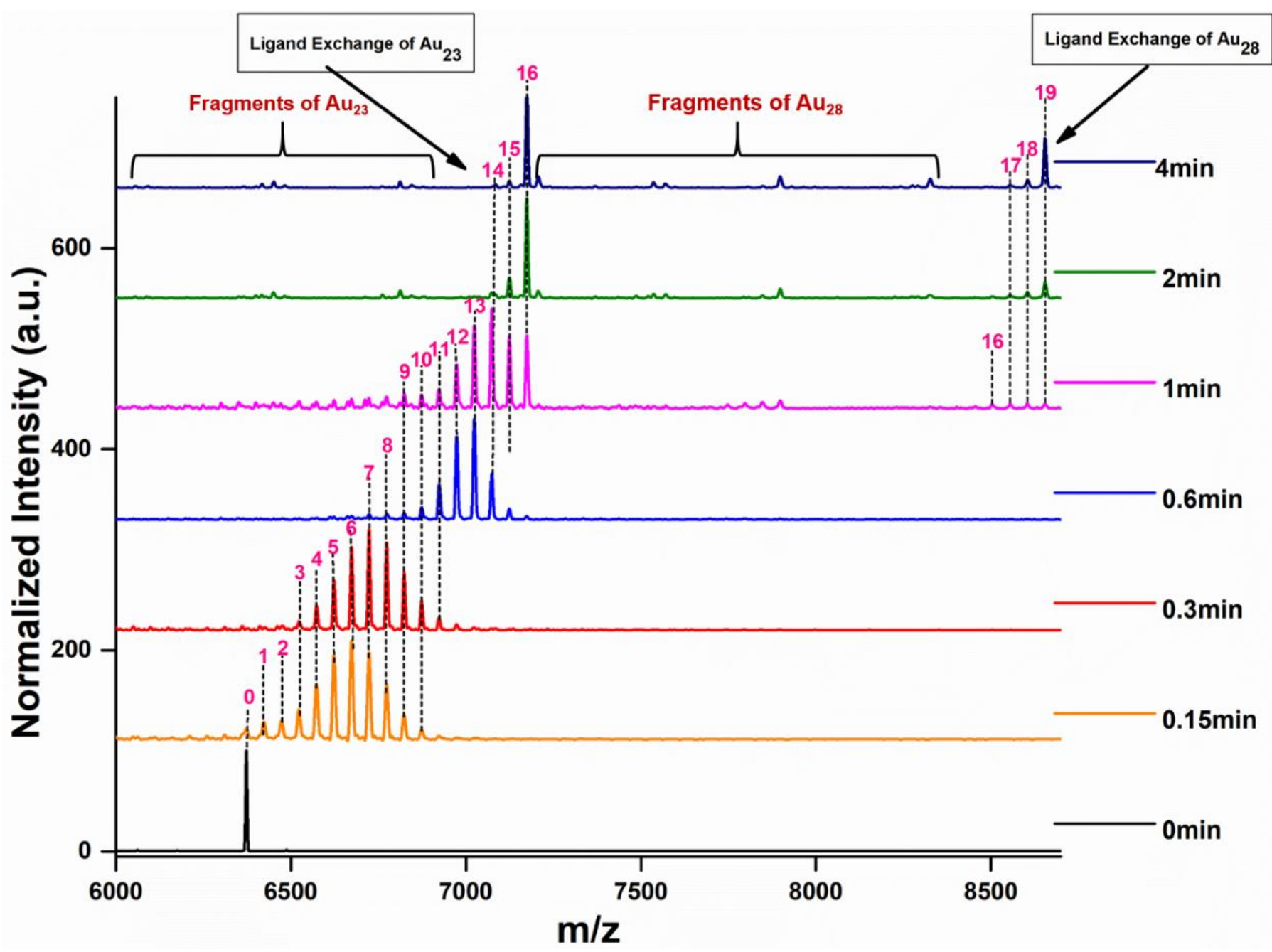

Figure S7. Time- dependent MALDI-MS data showing ligand exchange until 4 minutes. 


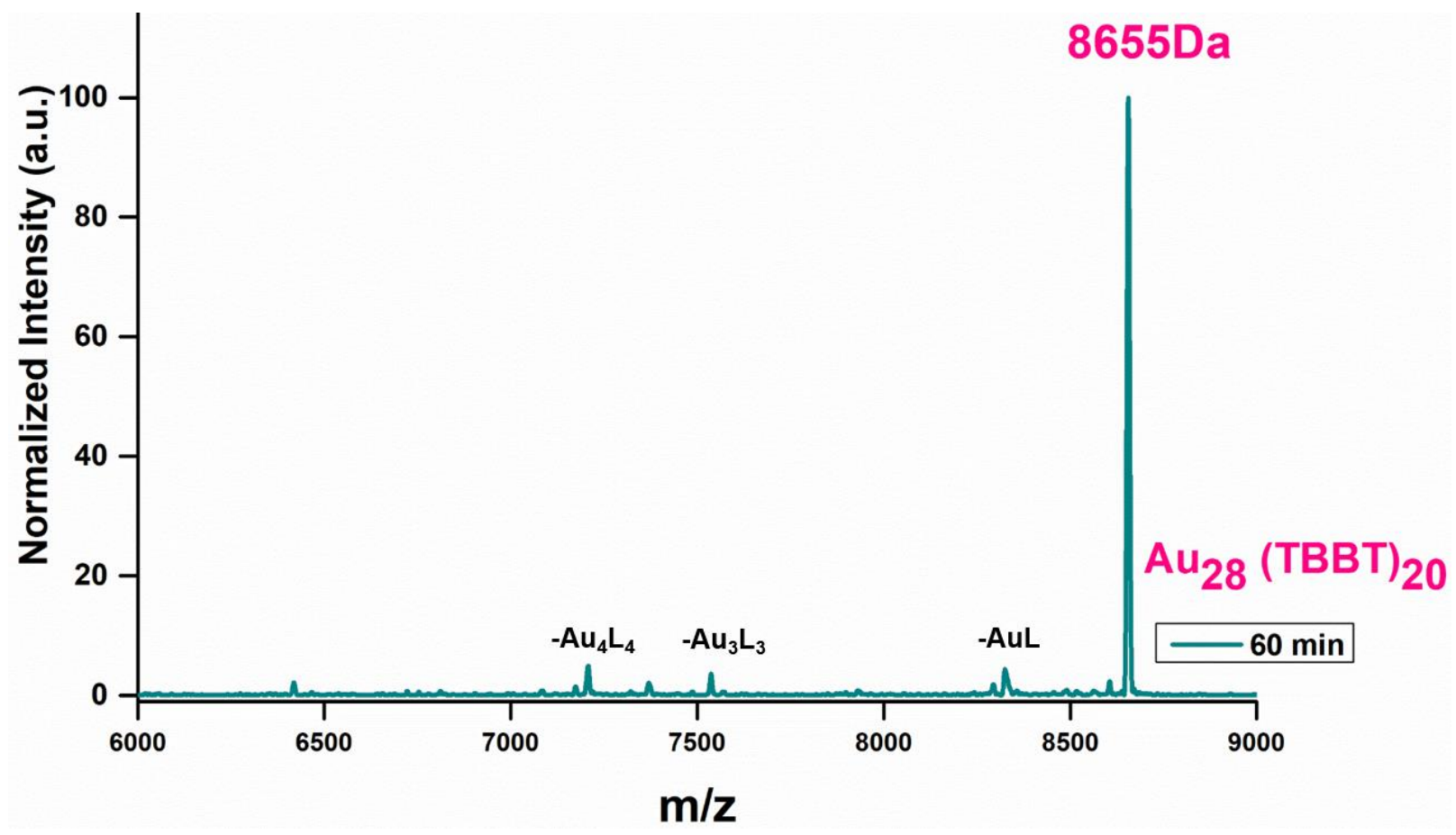

Figure S8. MALDI data showing the molecular purity of the daughter cluster i.e. Au28(TBBT)20. 


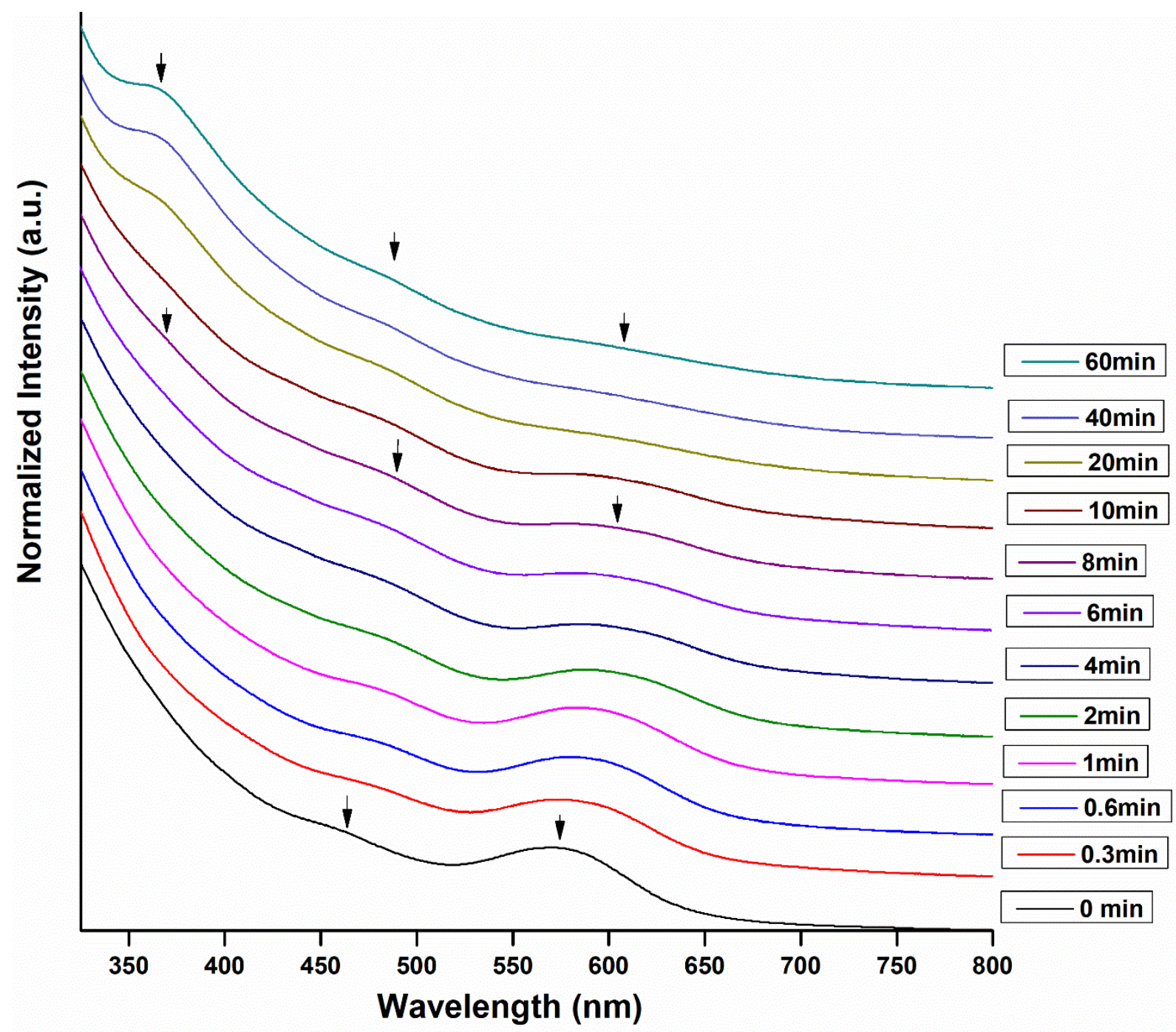

Figure S9. Time dependent UV-Vis spectral data for the mechanistic study of stage 1 transformation. 


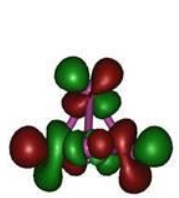

номо

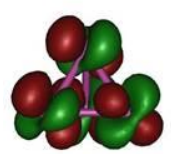

HOMO-4

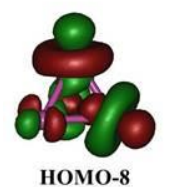

Occupied states of $\mathrm{Au}_{4}{ }^{2+}$ unit

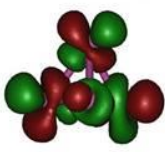

HOMO-1

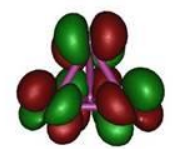

HОMO-5

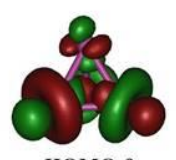

HOMO-9

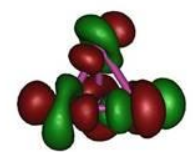

номо-2

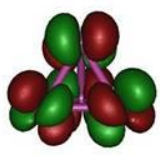

HOMO-6

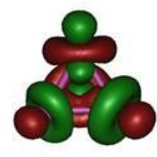

HOMO-10

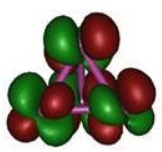

номо-3
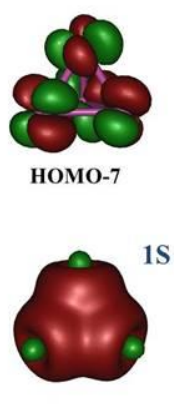

Hом0-11

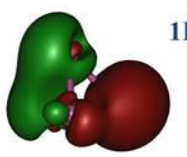

LUMO

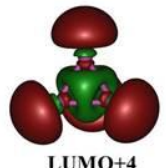

LUMO+4

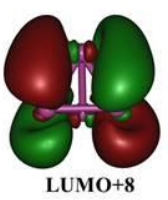

Unoccupied states of $\mathrm{Au}_{4}{ }^{2+}$ unit

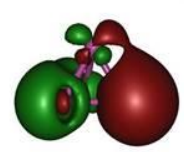

LUMO+1
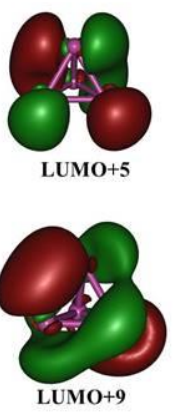

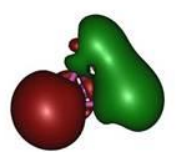

LUMO+2
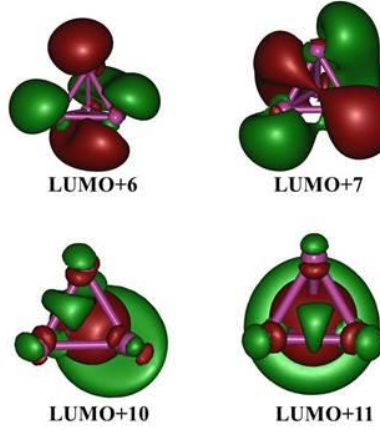

Figure S10: Molecular orbitals of $\mathrm{Au}_{4}{ }^{2+}$ fragment unit. The 1S and 1P superatomic orbitals are indicated. Brown and green colours represent positive and negative isosurfaces. 
Table S2: The free energy change associated with $\mathrm{Au}_{7}{ }^{3+}$ formation from fragment units.

\begin{tabular}{|c|c|}
\hline $\mathrm{Au}_{7}{ }^{3+}$ formation type & $\begin{array}{c}\text { Free Energy Change } \\
(\mathrm{eV})\end{array}$ \\
\hline $\begin{array}{c}\left(\mathrm{Au}_{4}{ }^{2+}+\mathrm{Au}_{4}{ }^{2+}\right)=\left(\mathrm{Au}_{7}{ }^{3+}\right. \\
\left.+\mathrm{Au}^{+}\right)\end{array}$ & 1.20 \\
\hline$\left(\mathrm{Au}_{4}{ }^{2+}+\mathrm{Au}_{3}{ }^{+}\right)=\mathrm{Au}_{7}{ }^{3+}$ & 0.50 \\
\hline
\end{tabular}




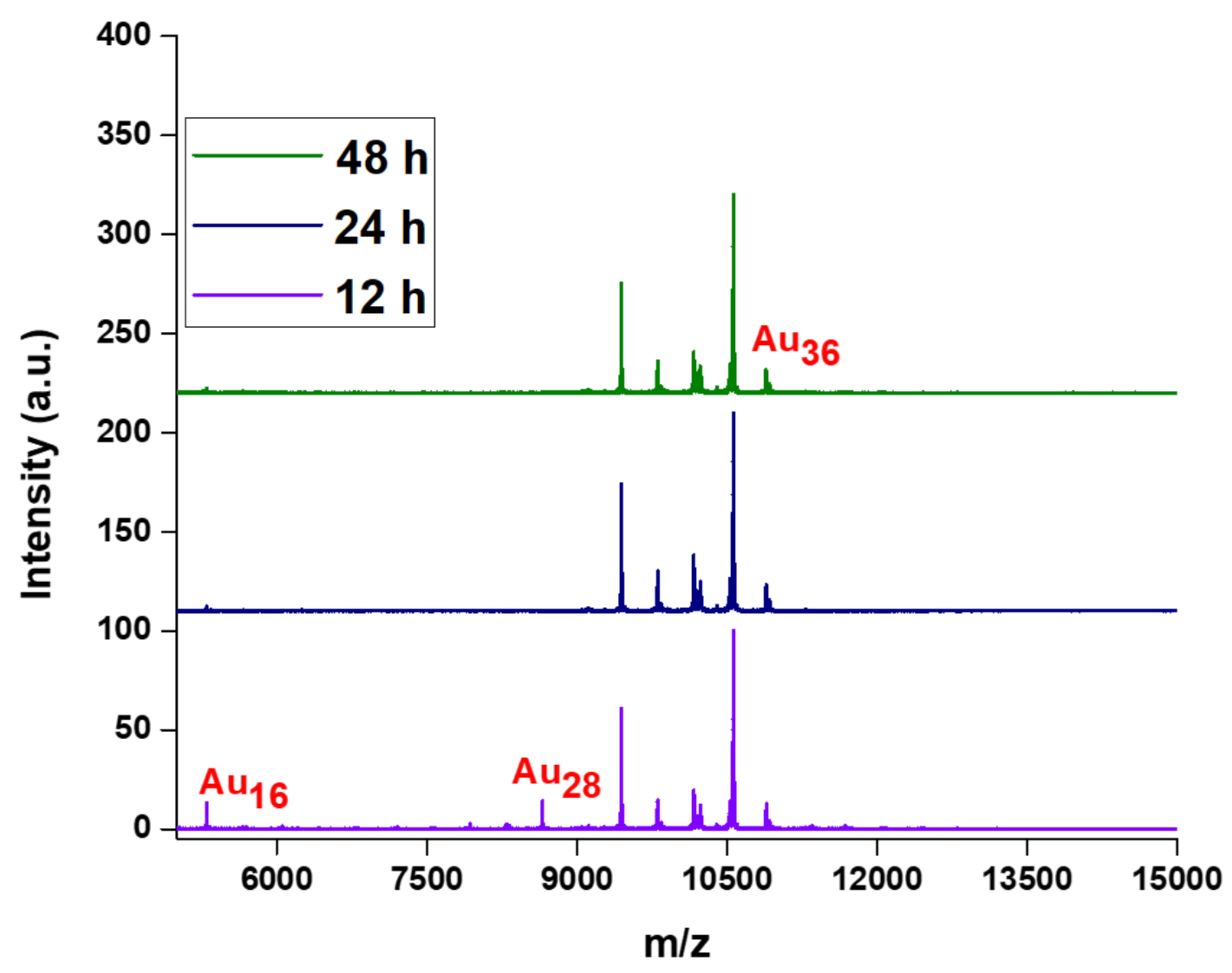

Figure S11. Time dependent MALDI-MS of $\mathrm{Au}_{28}$ to $\mathrm{Au}_{36}$ transformation showing the side product $\mathrm{Au}_{16}(\mathrm{TBBT})_{13}$ at $5299 \mathrm{Da}$, which is unstable at this reaction condition. 


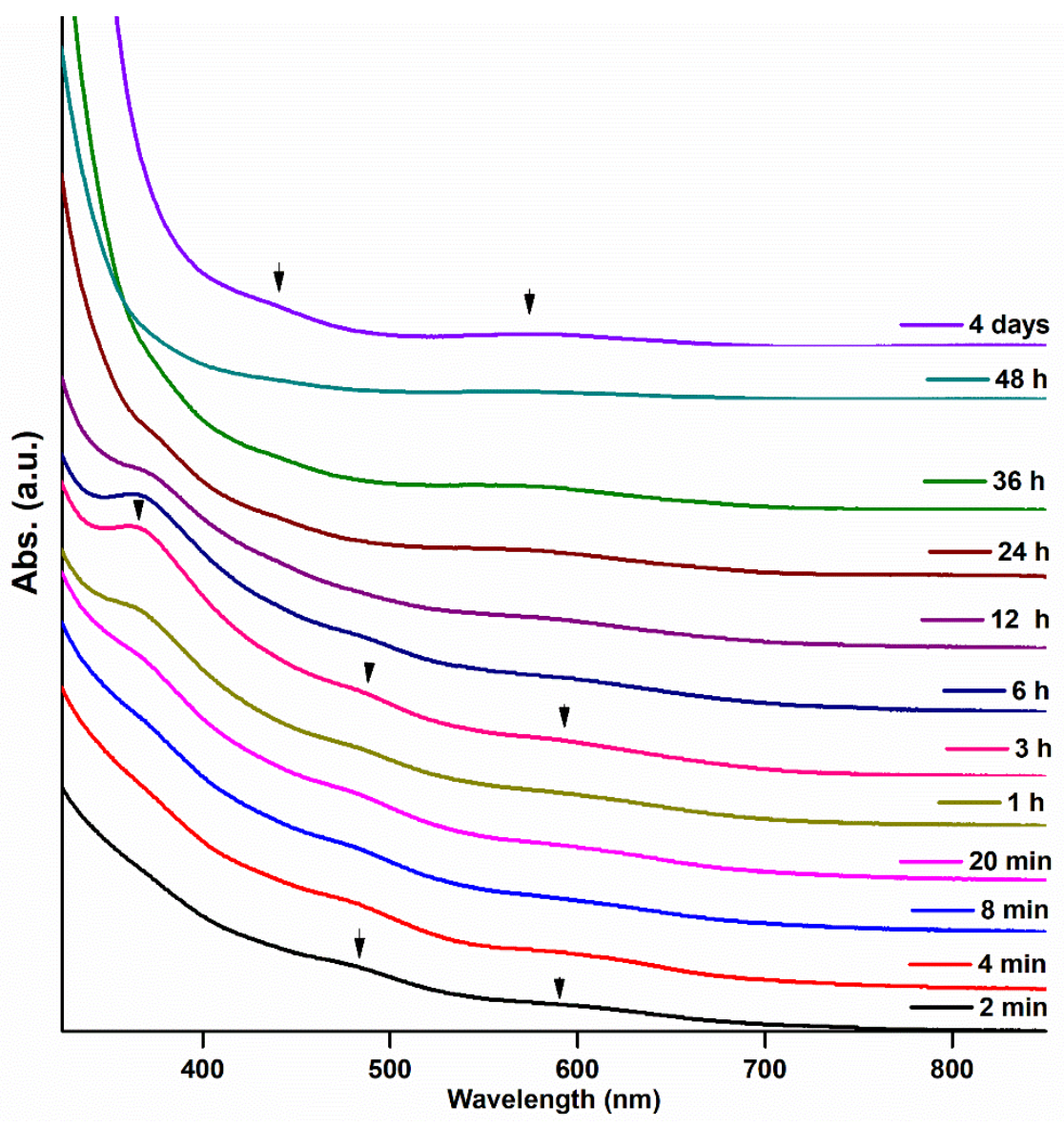

Figure S12. Time dependent UV-Vis spectral data for the mechanistic study of stage 2 transformation process. 
a)

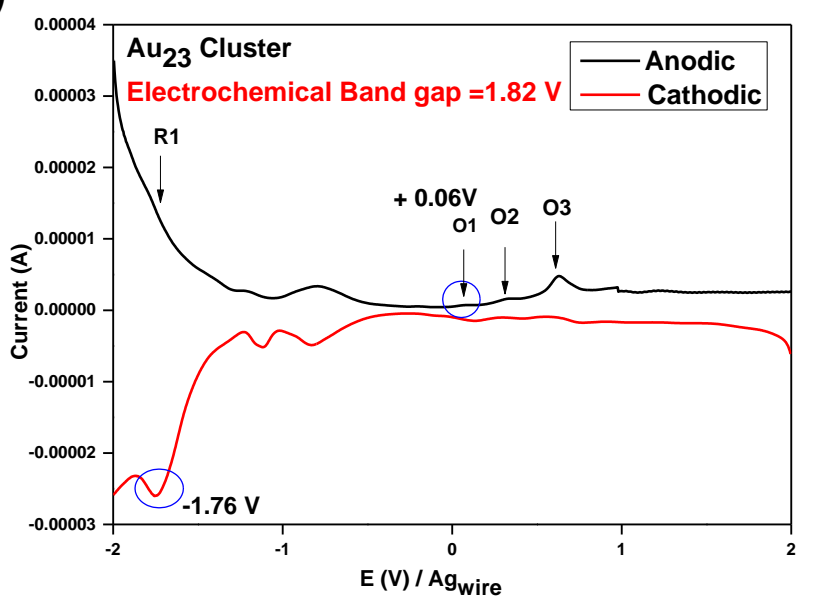

c) b)

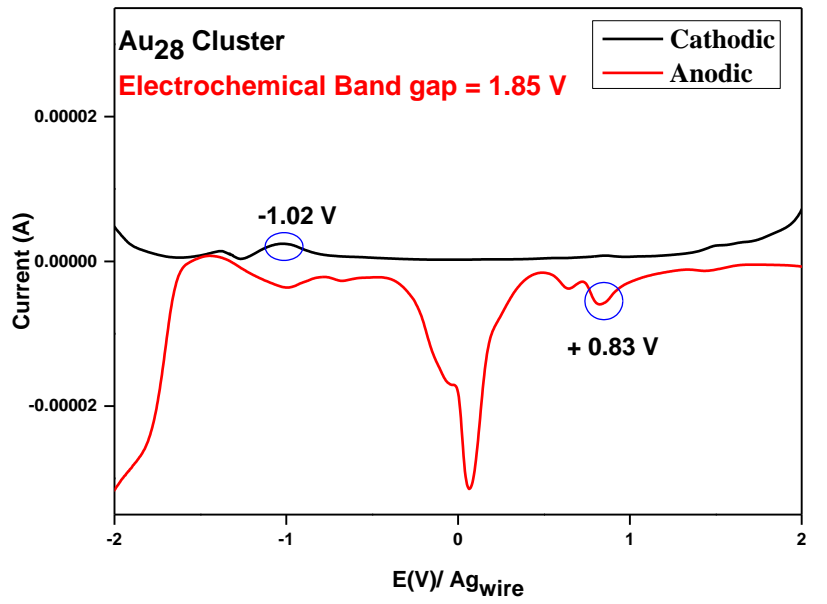

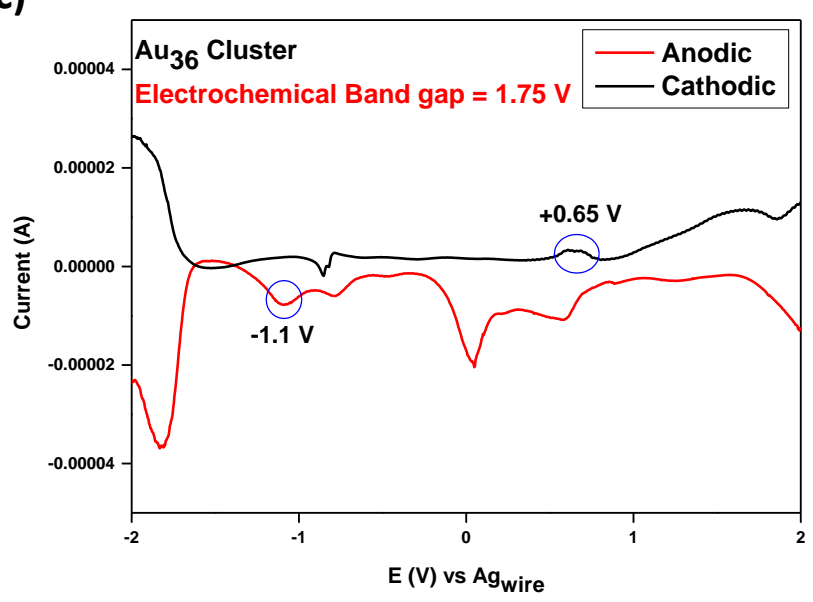

Figure S13. Differential Pulse voltammetry (DPV) of $\mathrm{Au}_{23}, \mathrm{Au}_{28}$ and $\mathrm{Au}_{36}$ labelled as a, b and c respectively, and their electrochemical band gap values. 


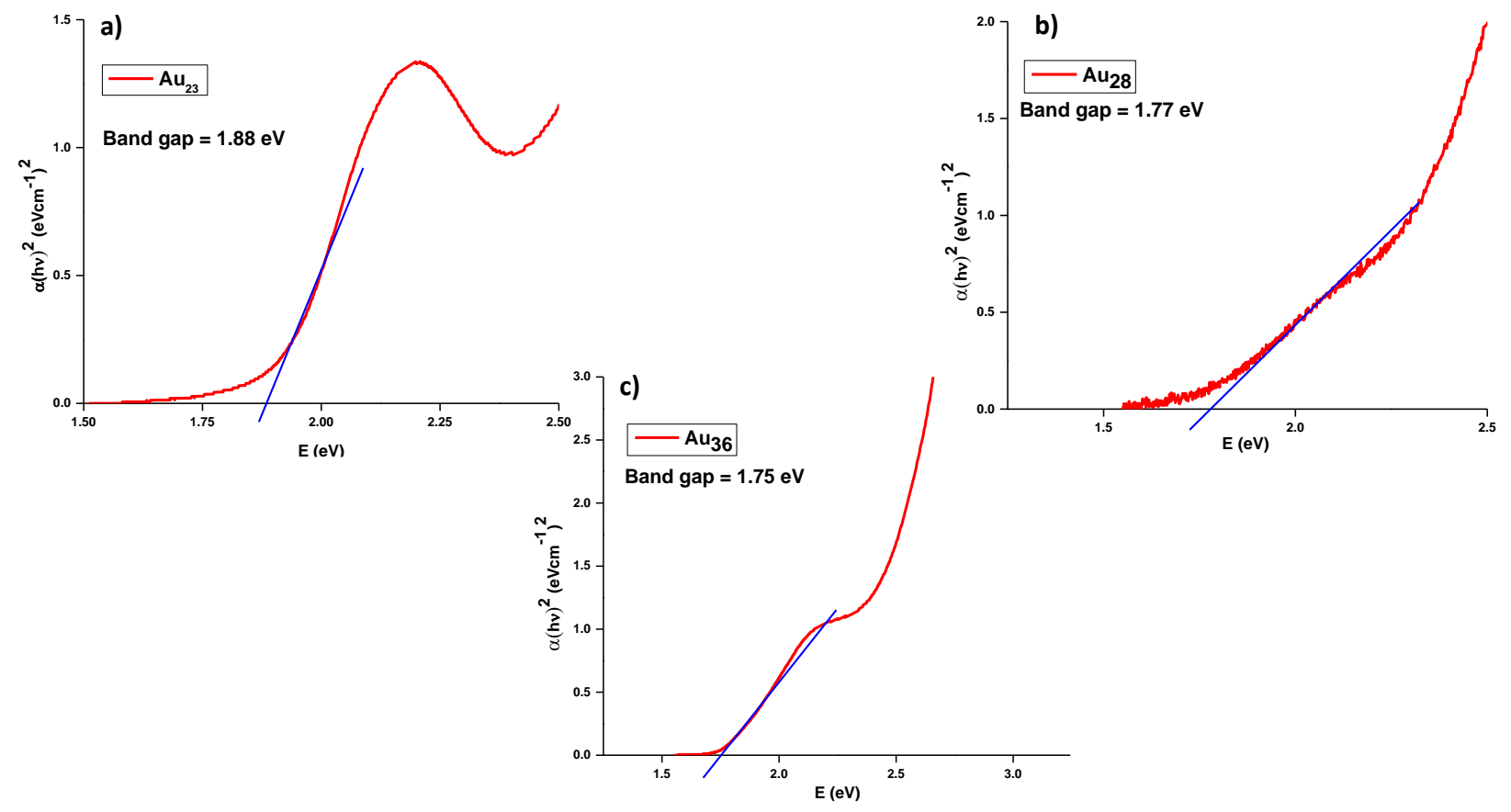

Figure S14. Tauc plot of $\mathrm{Au}_{23}, \mathrm{Au}_{28}$ and $\mathrm{Au}_{36}$ labelled as a, b and c respectively and the corresponding optical band gap values. 

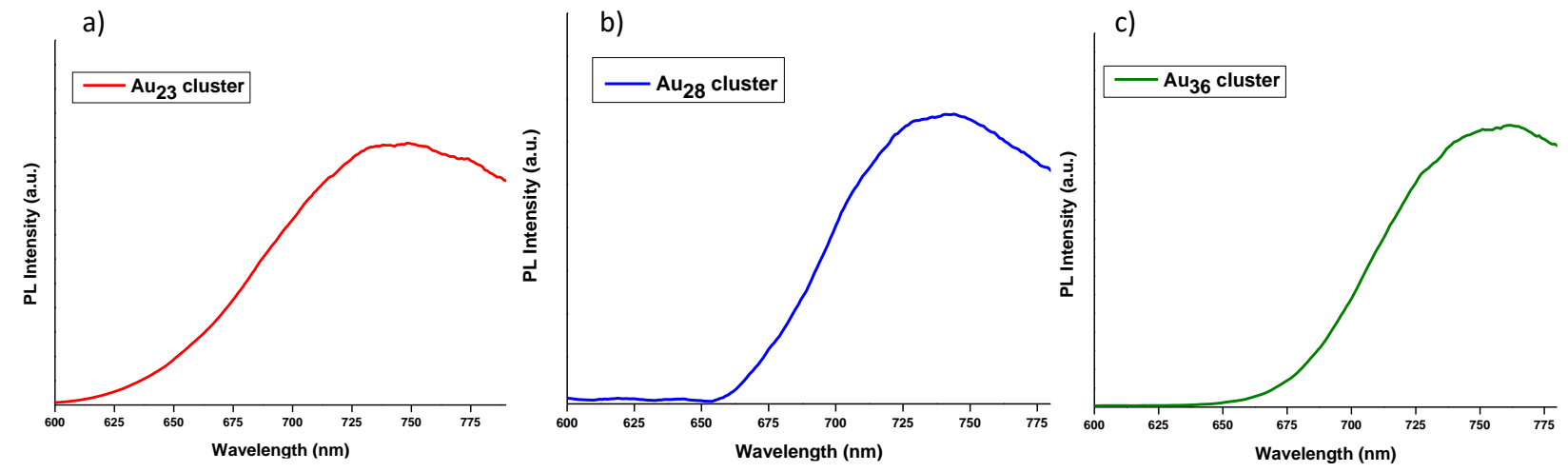

Figure S15. PL spectra of $\mathrm{Au}_{23}, \mathrm{Au}_{28}$ and $\mathrm{Au}_{36}$ nanocluster labelled as a,b and c, respectively. 

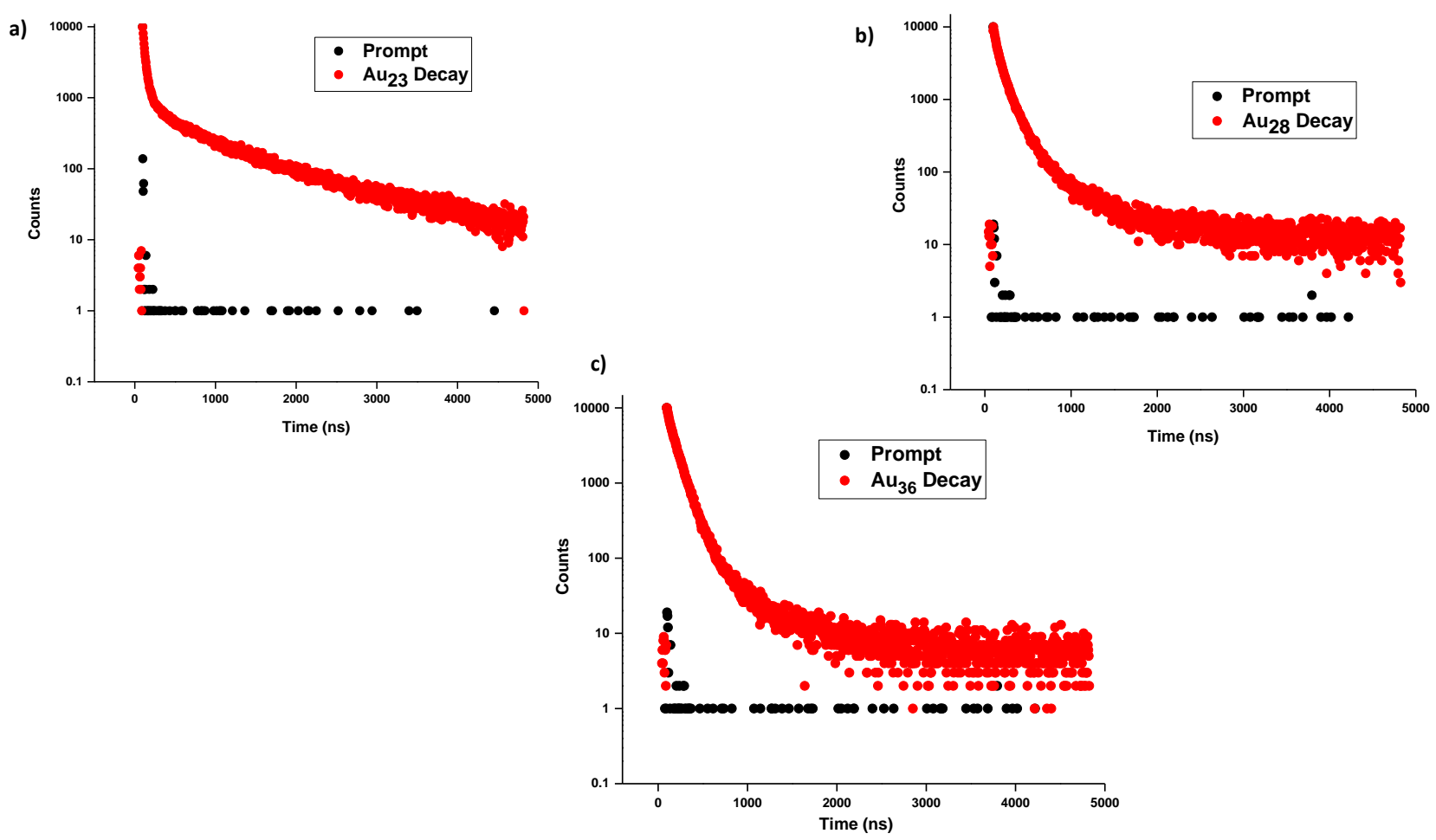

Figure S16. Lifetime measurement of the $\mathrm{Au}_{23}, \mathrm{Au}_{28}$ and $\mathrm{Au}_{36}$ nanocluster labelled as a, b and c, respecively. 
Table S3. Lifetime of Au23, Au28 and Au36, respectively

\begin{tabular}{|c|c|}
\hline Cluster & Life time $(\mathbf{n s})$ \\
\hline$\left[\mathrm{Au}_{23}\left(\mathrm{SC}_{6} \mathrm{H}_{11}\right)_{16}\right]^{-}$ & 30.3 \\
\hline $\mathrm{Au}_{28}(\mathrm{TBBT})_{20}$ & 82.3 \\
\hline $\mathrm{Au}_{36}(\mathrm{TBBT})_{24}$ & 108.0 \\
\hline
\end{tabular}

The observation of the lifetime was found to be in the opposite trend; according to the well-known energy gap law, as the H-L gap decreases, the carrier recombination times should decrease. ${ }^{\mathrm{S} 11, \mathrm{~S} 12}$ This reverse trend suggested that excited-state lifetimes cannot be correlated with quantum confinement effect. Our results are reminiscent with the recent report by Zhou et al, where they have evaluated the excited-state dynamics in series of periodic FCC clusters, and they summarized that (a) optical transition for those FCC series clusters is molecular-like inter-system crossing rather than core-shell relaxation, (b) with increment of size of the kernel both hot carrier relaxation and band-edge carrier recombination begin to be slower and that leads to longer-lived excited state. ${ }^{\mathrm{S} 13}$

\section{References:}

S11. Zeng, C.; Chen, Y.; Iida, K.; Nobusada, K.; Kirschbaum, K.; Lambright, K. J.; Jin, R. Gold Quantum Boxes: On the Periodicities and the Quantum Confinement in the Au28, Au36, Au44, and Au52 Magic Series. J. Am. Chem. Soc. 2016, 138 (12), 3950-3953.

S12. Lakowicz, J. R. Principles of Fluorescence Spectroscopy, 3rd ed.; Springer: New York, , 2006.

S13. Zhou, M.; Zeng, C.; Sfeir, M. Y.; Cotlet, M.; Iida, K.; Nobusada, K.; Jin, R. Evolution of Excited-State Dynamics in Periodic Au28, Au36, Au44, and Au52 Nanoclusters. J. Phys. Chem. Lett. 2017, 8 (17), 4023-4030 